\title{
The use of Terrestrial Laser Scanning for the purposes of preparing technical documentation in BIM technology
}

\author{
Lukasz Uchański ${ }^{1}$, Krzysztof Karsznia ${ }^{2}$ \\ ${ }^{1}$ Czerski Trade Polska Sp. z o.o., Al. Niepodległości 219, 02-087, Warsaw \\ e-mail:l.uchanski@czerski.com \\ ${ }^{2}$ Department of Civil Engineering, Faculty of Civil and Environmental Engineering \\ Warsaw University of Life Sciences - SGGW, e-mail: Krzysztof_Karsznia@sggw.pl
}

\begin{abstract}
Building Information Modelling (BIM) is becoming an increasingly popular solution used both for investment and for reverse engineering aimed at restoring of the original documentation of existing facilities. The reconstruction of an object including its full design properties in an interactive $3 \mathrm{D}$ environment makes it possible to carry out structural (including SMH - structural health monitoring) and strength analyses, as well as to provide the efficient facility management (setting out essential parameters and conducting necessary repairs). This paper aims to assess the laser scanning performed by using an advanced pulse data-capturing device for the development of complex BIM documentation in the Water Centre Laboratory of Warsaw University of Life Sciences - SGGW. Obtained point clouds have been used to build the model for the needs of reverse engineering. Moreover, the authors evaluated the possibility of using a particular type of laser scanner to develop and update complex BIM documentation in the process of facility management.
\end{abstract}

Keywords: Terrestrial Laser Scanning, BIM, inventory works, Laser Scanning, point cloud, 3D model.

\section{Introduction}

Building Information Modelling, which is also known as Building Information Management, in short - BIM - is becoming steadily significant and evolving into the benchmark in the domain of construction investment in developed countries [5,7]. It embraces each phase of the process - starting from the design stage, execution phase, to reception and usage of the facilities [11]. A virtual environment with detailed information considering all three dimensions constitutes a working platform that makes it possible to update the design during its execution. Such as approach brings numerous benefits. One of the key advantages is easy access to information - the most important aspect for designers, engineers, contractors and facility managers [12]. In the context of BIM, besides the design data of an investment in the construction phase, the crucial points are surveying and cartographic resources, especially a base map considered as its fundamental element [3]. The integration of surveying and cartographic resources with a BIM system starts with importing a vector map. Then, on its basis, it is possible to generate a specific spatial model which may be used for further design works. Assuming that, such technology as BIM allows for the exchange of experiences, knowledge 
and design information without any hindrance - we may use a full access to the current information about the phase and shape of the investment. However, it is not always possible to use BIM from the beginning of the investment process $[7,12]$. In such case, it is important to reproduce primary design documents with the use of inventory works of the conditions of a facility and presentation of the works in 3D by implementing the advanced technologies of the reverse engineering [15]. The next phase, being the cutting-edge solution, is further integration of obtained models with BIM technology.

\section{The goal of the measurement}

The existing building - the Water Centre Laboratory of Warsaw University of Life Sciences - SGGW (Fig. 1) was partly inventoried with the use of 3D laser scanning technology. Thanks to the above technology, a vast set of information reflecting actual geometry of the object, as well as the construction details of its roof structure were collected in quite a short time (Fig. 2).
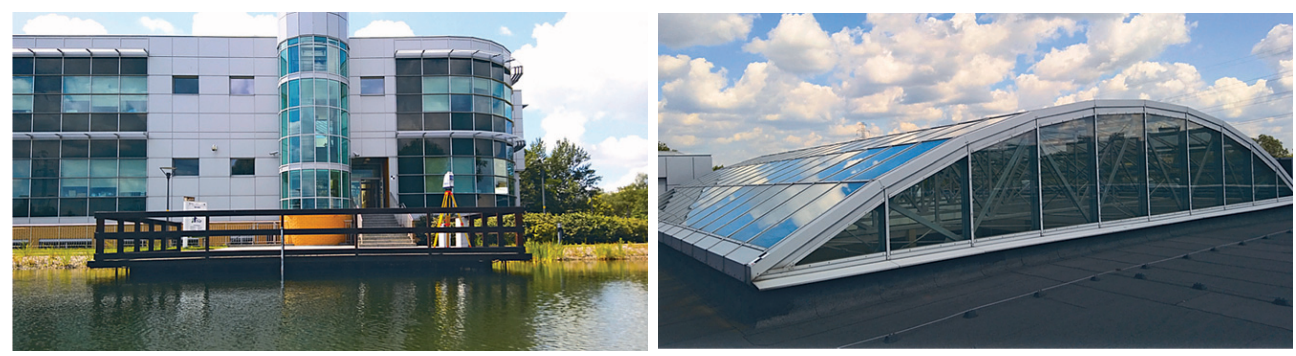

Fig. 1. View of the Water Centre Laboratory, Warsaw University of Life Sciences - SGGW (photo by Krzysztof Karsznia)

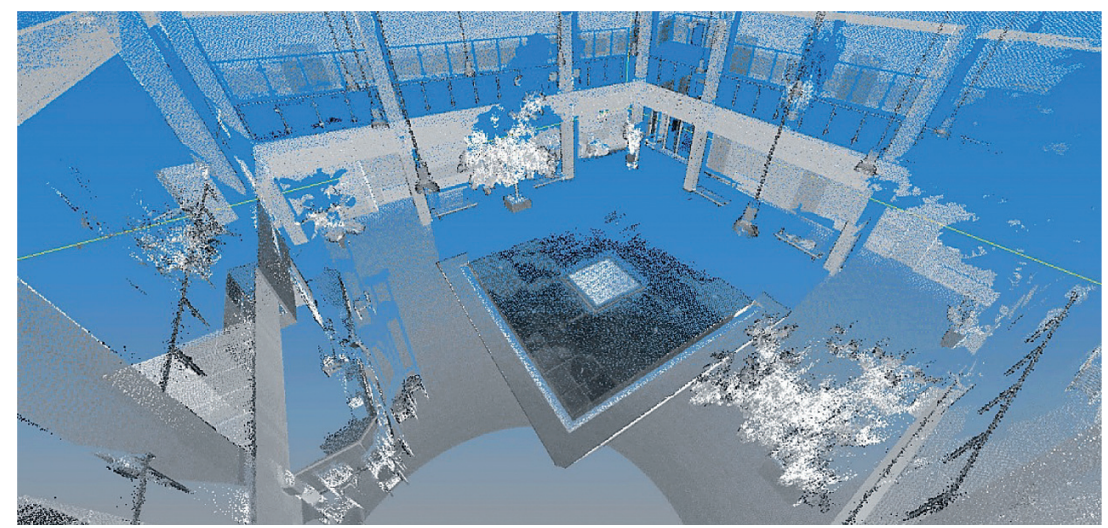

Fig. 2. View of the point cloud registered during laser scanning of the Water Center Laboratory, Warsaw University of Life Sciences - SGGW (own elaboration)

The scanning aimed to measure the interior of the building. The works that were performed are the continuation of the similar examinations made by the authors for other industrial buildings, which were described in [13]. Based on the conducted measurements, the 
prospect of using scanning results to create the complex BIM documentation and its further development for the purpose of the facility management was assessed. The results of the scanning enabled the authors to verify to what extent it is possible to use Terrestrial Laser Scanning to the development of BIM model of the building of the Water Center Laboratory of SGGW and the fragments of its roofing construction. This verification facilitates preparation of the initial assumptions for further works, which aim at clarification of the scope of the future use of BIM technology for similar buildings.

\section{Object characteristics and the scope of works}

The Science and Didactic Centre of the Faculty of Civil and Environmental Engineering of Warsaw University of Life Sciences - SGGW, the Water Center Laboratory is located in the main campus in Ursynów - one of the districts of Warsaw. The total surface of the buildings is approx. $14600 \mathrm{~m}^{2}$ (Fig. 3). This includes the educational centre with the surface of $1954.8 \mathrm{~m}^{2}$ and the cubature of $28167 \mathrm{~m}^{3}$. There are a total of 19 didactic rooms, exposition halls and the patio with the source of Oligocene, Pleistocene and tap water [8]. This building was selected for research because of its design characteristics and roofing structure.

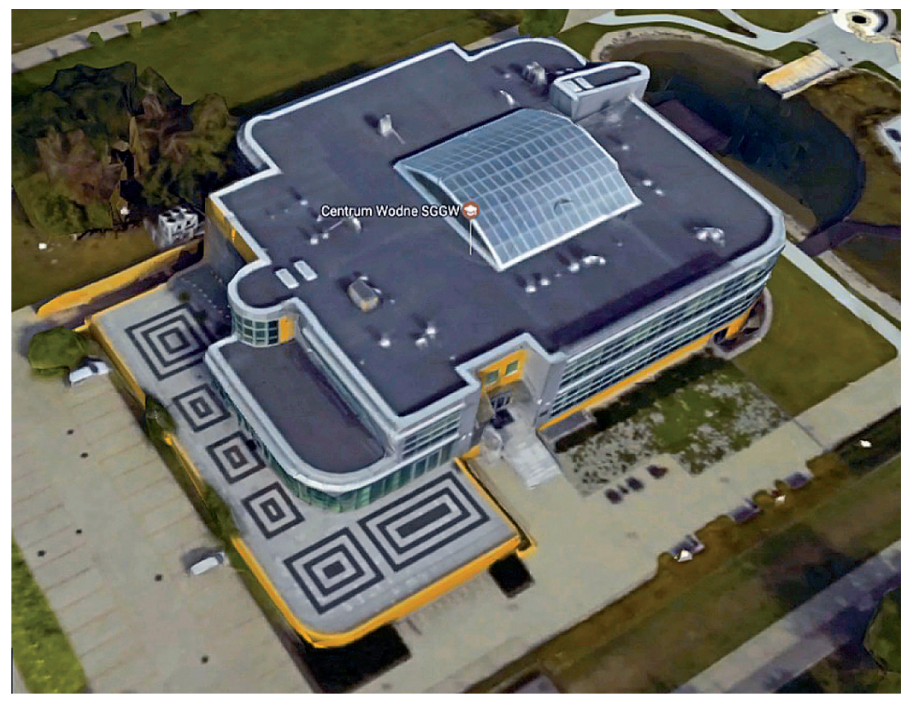

Fig. 3. View of the Water Centre Laboratory, WULS-SGGW, source: Google Maps

Before starting measurements, other technologies of spatial data acquisition were considered, e.g. classical tacheometry and photogrammetry. However, due to the requirement to provide complex, reliable and recurrent data at high accuracy level - considering also the time necessary to perform analysis, the authors decided to use the technology of pulse laser scanning $[10,14]$. The laser scanner is equipped with a scanning head emitting a laser beam projected onto adjacent surfaces. The scope of the device might be freely modified - it might be even $360^{\circ}$ in a horizontal plane and $90^{\circ}$ in a vertical plane, giving the point cloud, which represents all accessible space to analyse. The speed of scanning head provides the measuring resolution even up to 1 million points per second (in our case it was around 40 thousand points per second). These parameters mainly depend on the type of scanner (pulse or phase 
type device) $[9,14]$. The working principle of pulse instruments is the precise measurement of a period between the emission and the return to a reading system of the emitted pulse of a laser beam. Whereas, in the case of phase scanners, it is the phase of the carrier wave that is subjected to measurement. As a result, the so-called point cloud is registered with spatial coordinates $(\mathrm{X}, \mathrm{Y}, \mathrm{Z})$ and Intensity Image information - the reflection of the beam on the surface [6]. Therefore, the choice of the most suitable technology depends on the required time of the measurement, scope and estimated accuracy. The clear advantage of laser scanning comparing to tacheometry is that it gives much more points, saves time and is efficient. The measurements were made with the use of pulse laser scanner 3D Stonex X300 (Fig. 4). This instrument is a middle-range device prepared to work in industrial, housing and cubature facilities as well as in topographic surveys.
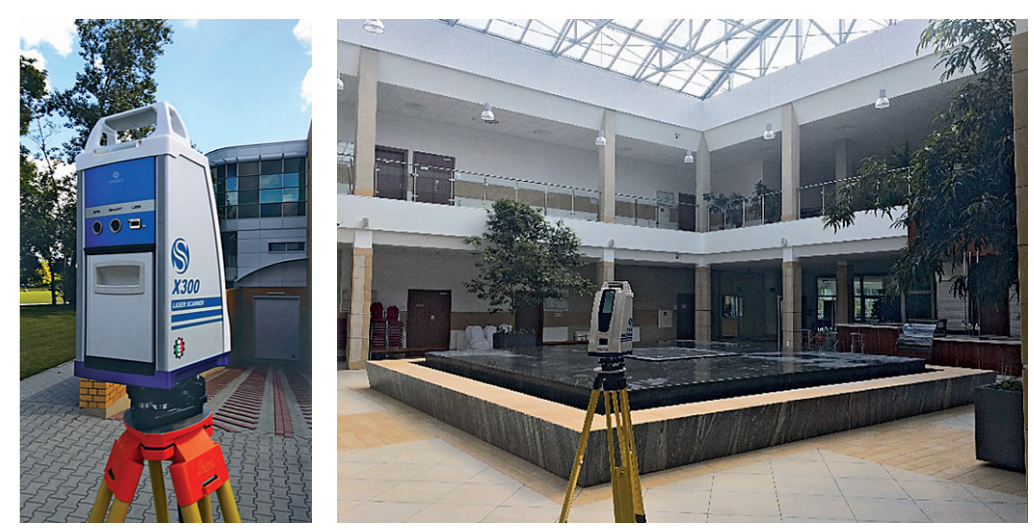

Fig. 4. View of a laser scanner Stonex X300 at the test site (photo by Krzysztof Karsznia)

Table 1. Technical data of Stonex X300 laser scanner (source: [10])

\begin{tabular}{ll}
\hline \multicolumn{1}{c}{ Feature } & \multicolumn{1}{c}{ Parameters } \\
\hline Range & $1.6-300 \mathrm{~m}$ by $100^{\circ}$ albedo (for white) \\
\hline Working range in a horizontal plane & $360^{\circ}($ fully panoramic) \\
\hline Working range in a vertical plane & $90^{\circ}\left(-25^{\circ}\right.$ to $\left.+65^{\circ}\right)$ \\
\hline Scanning speed & to 40000 points $/$ second \\
\hline Grid size & $39 \mathrm{~mm} \times 39 \mathrm{~mm}$ at $100 \mathrm{~m}$ \\
\hline Laser spot size & $0,37 \mathrm{mrad}$ \\
\hline Angular resolution & $1.35^{\prime}(\mathrm{H}) \times 1.35^{\prime}(\mathrm{V})($ at maximal resolution $)$ \\
\hline Distance measurement accuracy & $<6 \mathrm{~mm}$ on $50 \mathrm{~m}-(1$ sigma) \\
\hline Scanner optics & $<40 \mathrm{~mm}$ on $300 \mathrm{~m}$ \\
\hline Laser class & $\begin{array}{l}\text { mirror rotating vertically, } \\
\text { base rotating horizontally }\end{array}$ \\
\hline Length of the laser beam & Class $1 \mathrm{M} 9 \mathrm{IEC} 60825-1$ \\
\hline Dual-axis compensator & $905 \mathrm{~nm}($ invisible $)$ \\
\hline Integrated camera resolution & accuracy $0.08^{\circ}$, range $+/-20^{\circ}$ \\
\hline Scanner weight and size & $5 \mathrm{MPix}$ \\
\hline Work temperature & $6.15 \mathrm{~kg}, 215 \mathrm{~mm} \times 170 \mathrm{~mm} \times 430 \mathrm{~mm}$ \\
\hline
\end{tabular}


The choice of scanning device was determined by various factors such as measuring accuracy, scanning range and quick response. 3D scanner Stonex X300 is characterised by the accuracy of points positioning less than $\pm 5 \mathrm{~mm}$ for the target length of $50 \mathrm{~m}$ (Table 1 ). Moreover, this scanner is light and might be operated a long time using battery power (up to 6 hours). That is why this technology meets all requirements for this type of projects.

Elaboration of the data - point clouds obtained during scanning was made with the use of the software JRC 3D Reconstructor in the newest available version 3.2.1.587 [10]. The virtual platform used for this purpose provided the opportunity to fully and thoroughly process the data obtained by laser scanning. The software was used to make initial registration of the data - i.e. conversion to the format compliant with the requirements of the operational environment of the software. Point clouds from all stands of the scanner were connected into one, standard, balanced coordinate system with the accuracy of $\pm 5 \mathrm{~mm}$. For the purpose of this analysis, the authors decided to work in the local coordinate system without joining of registered point clouds to the geodetic benchmarks. When there was a need to make so-called georeferencing, special target plates (Fig. 5) were used. Coordinates of their centres were determined with the use of precise electronic total-stations.

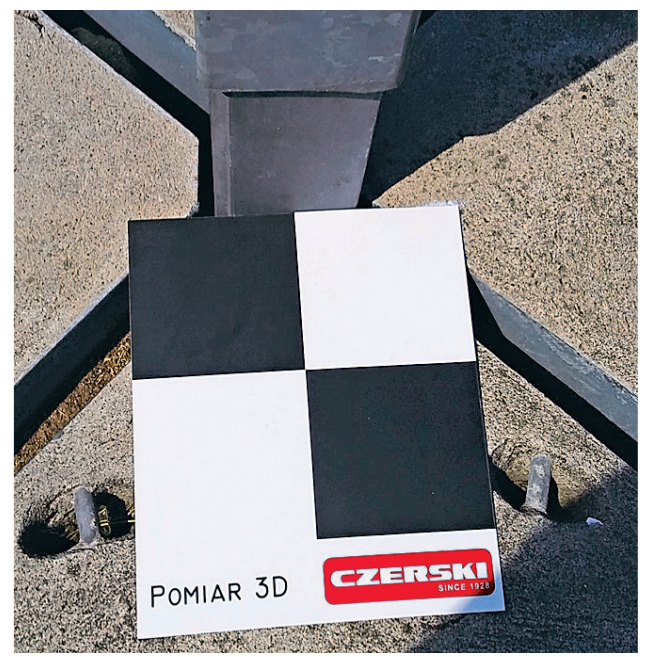

Fig. 5. View of example target plate used for matching point clouds into geodetic reference framework (photo by Krzysztof Karsznia)

Then, the registered data was filtered, and all noises and artefacts that had appeared during measurement were deleted. 3D documentation and the models were developed with the use of Autodesk Design Building Suite Premium 2017 program package. The first step was indexing and optimising of point clouds converted to unique format e57 in Autodesk RECAP 360 program. The second step was the implementation of indexed clouds to Autodesk REVIT 2017 program. The last stage contained the development of three-dimensional models on the basis of which the authors formulated the recommendations for the practical use of these technologies. 


\section{Results}

The conducting of terrestrial laser scanning shows that the way of performing measurements has an impact on quality, accuracy and cohesion of registered data. Thereby, they affect the accuracy and reliability of the complex 3D model developed in BIM technology [8]. Selection of the most suitable scanner (pulse or phase) and proper planning of its stands influence the work effectiveness and determine the total cost of the analysis. That is why it is recommended every time to prepare and verify the project of data acquisition in situ before starting planned measurement works. The result of the measurements achieved during this analysis was ten scans made with the horizontal angle of $360^{\circ}$ and four scans with a horizontal angle of $100^{\circ}$. This contradistinction resulted from the location of the scanning stands and their direct environment (i.e. all obstacles which made scanning difficult). A total of 122 Million of measurement points were registered. In case of 10 scans made with the full horizontal angle, the only value that was used was registered reflectance; whereas, in case of 4 angular scans with lower registration angle, additionally coloured RGB pictures were taken in order to depict the interior of the scanned object. All scans were made within the main hall and its fountain (Fig. 6).

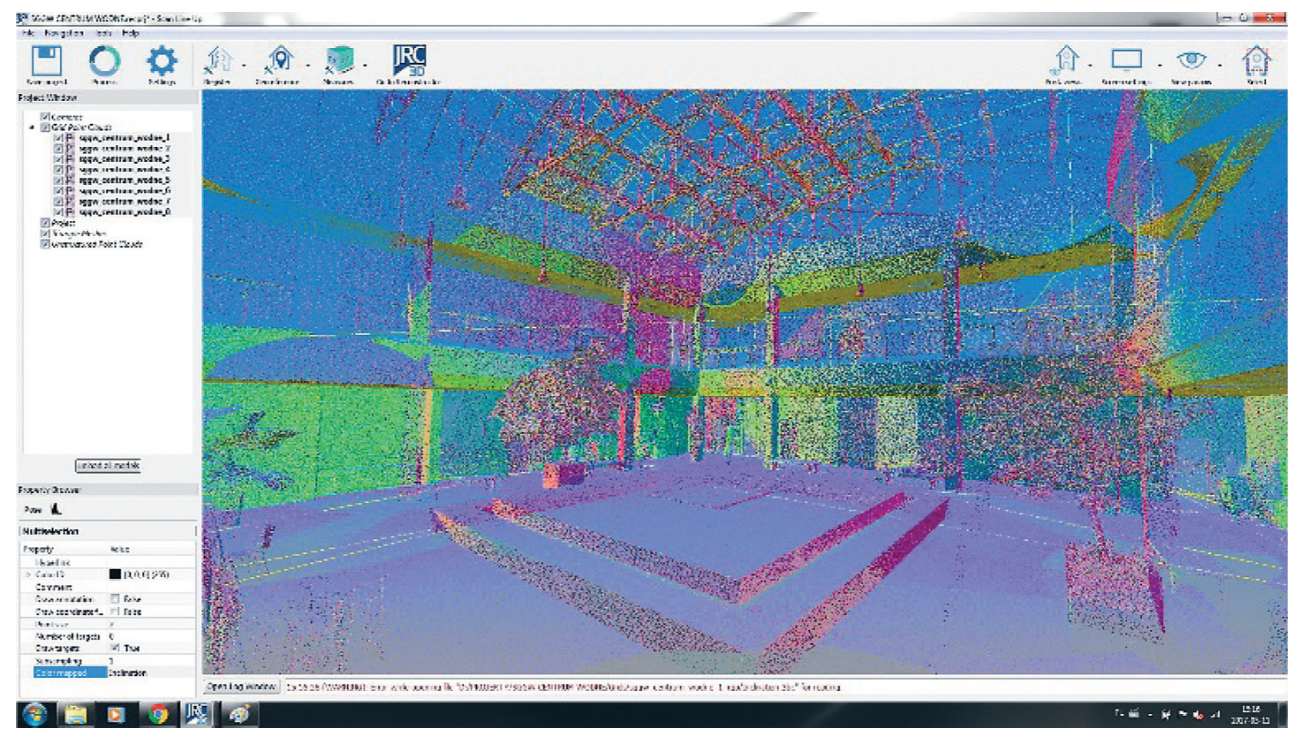

Fig. 6. View of matched laser scans depicting the main hall of the Water Centre Laboratory, WULS -SGGW in Warsaw, presenting mutual planes (own elaboration)

According to the description of the conducted steps, the collected data was adapted and then processed through spatial modelling to develop the overview documentation in BIM technology. Based on the collected materials, the set of cross-sections, 3D views and diagrams documenting the construction of the roofing directly over the mezzanines in the main hall were prepared. Once subcontractor documentation was analysed, it was acknowledged that it works very well as a starting material both for development of the full BIM model of the whole building of the Water Centre Laboratory of SGGW (Fig. 7) and for designing of the real-time potential structural health monitoring system (SHM). 


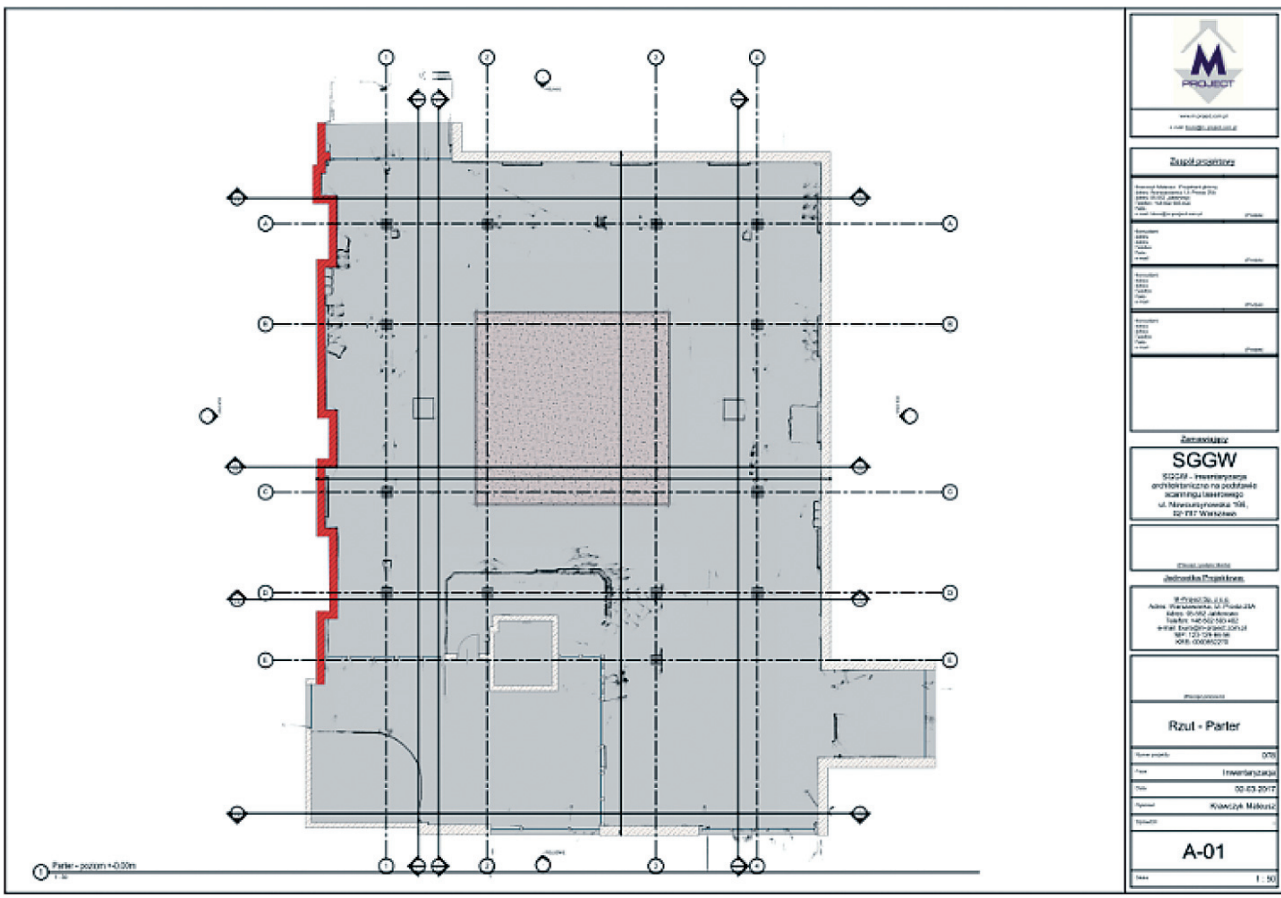

Fig. 7. View of the zero-level cross section produced in BIM technology (own elaboration)

Final accuracy of the elaborated 3D model is directly related to the accuracy and quality of initial data used for its elaboration. The scans were registered by defined contour points, edges and angles of a scanned object. In the case of the places for which it was difficult or impossible to identify registered contour of an object, the authors made their approximation with coordinates of extreme points with the use of specific program tools. Thus, it might be concluded that the accuracy of elaboration of the whole model is identical with the accuracy of available data coming from laser scanning (obtained point clouds).

\section{Application possibilities}

\subsection{Design and management}

3D model in BIM technology is supplemented with new information. As a result, we obtain a complex geoinformation structure based on which it is possible to undertake further, decisive actions [7]. Technical parameters of the material, chemical composition and age of a particular element, as well as other information in the documentation, make it possible to immediately verify maintenance assumptions of said construction element in terms of its exchange, repair, elimination or renovation [2]. Having such a complex database integrated with both technical drawings, cross-sections (Fig. 8), and the full model existing in three-dimensional environment, we can directly obtain necessary data for example to prepare a proposal to purchase special paint and to order the service of painting of selected surface of construction elements $[5,7,11]$. 


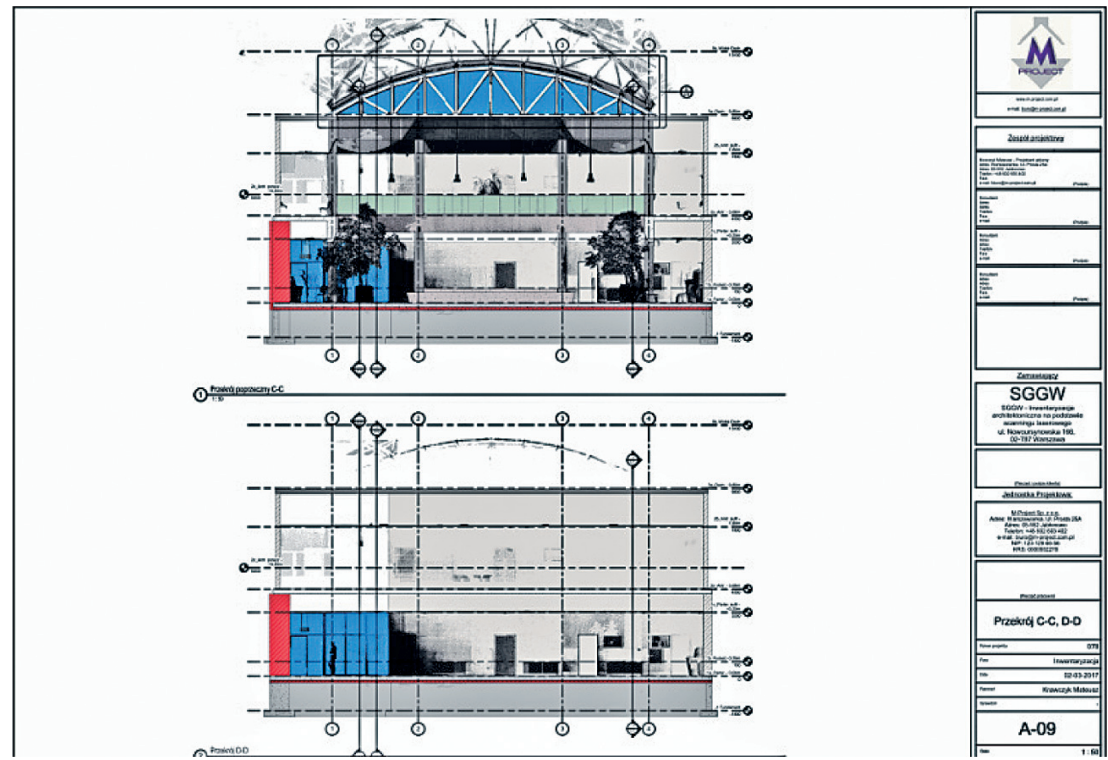

Fig. 8. Set of vertical cross-sections of the Water Centre Laboratory, WULS-SGGW (own elaboration)

The exchange of information regarding all aspects of administration and maintenance of a building between the parties concerned is simplified, and the possibility to automatically generate the reports, views and schemes facilitates the decision process, which helps to save means indispensable to conduct the whole procedure [4]. Taking into account the possibility to use said solution for the maintenance of a building, if we supplement the building model with parameters which relate to ventilation of a building or audio-visual equipment, we will inevitably move towards development of the full geographic information system (GIS) for a building. This solution is consistent with the design concept of "Smart Buildings", the part of "Smart Cities" - the project being nowadays the subject of many tests and studies all over the world.

\subsection{Structural health assessment}

The complex 3D model performed in BIM technology has also practical use in combination with Structural Health Monitoring (SMH) and Building Management System (BMS). In order to work properly, SMH and BMS as the system solutions need a complete database with information about a building with correctly defined emergency thresholds. The use of geographic information databases, which join 3D geometry from laser scanning and GIS data with geographic information (including static information) broadens considerably the possibility to use integrated, "multidimensional" BIM methodology. Thereby, it is additionally enriched with a broad layer of information describing a particular object in the space, which is particularly useful during its further maintenance. In order to select and define the location of the SHM system installation correctly, it is necessary to prepare the design and identify the installation place of every sensor. If for any reason it is necessary to use the monitoring in certain places, the periodic measurements might be undertaken with the use of geodetic methods (tacheometry, close-range photogrammetry). After choosing the suitable location, the development of the project of SHM system referring to the character of a particular 
construction will not require looking for the original design, but only enriching of information layer of a current BIM model. This model gives the possibility to virtually map separate sensors, as well as to identify with them the automatic visualisation of the measurements (Fig. 9 and 10).

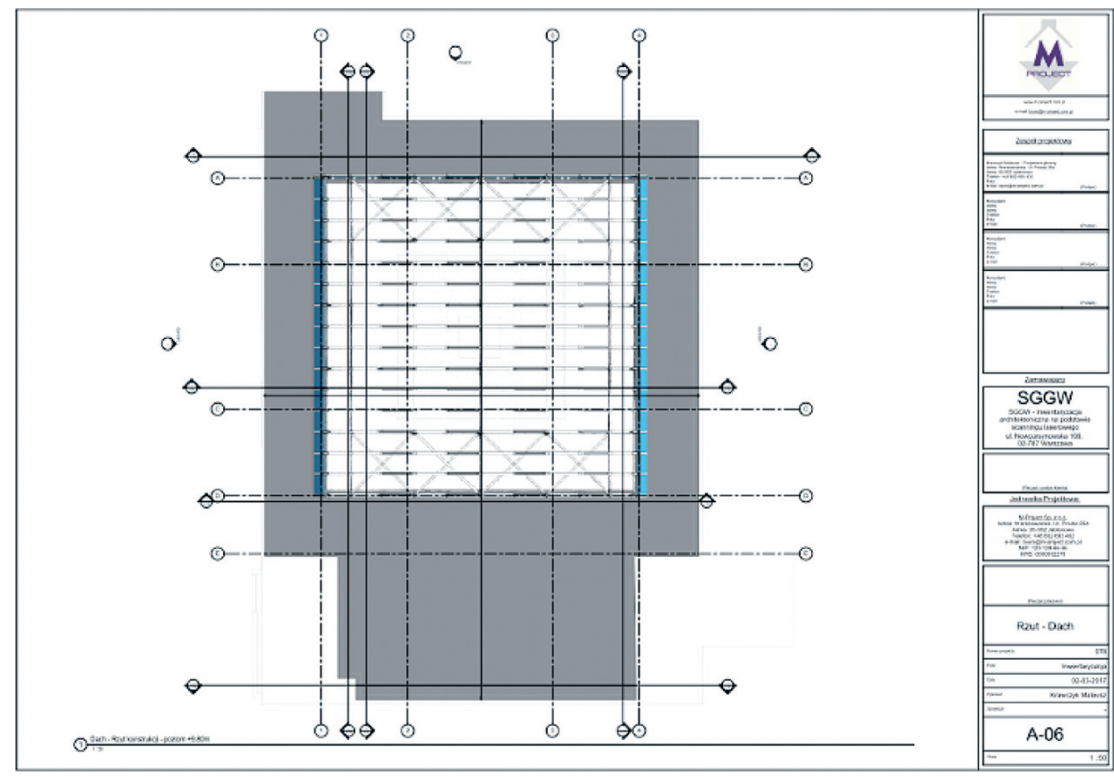

Fig. 9. Planar view of the roof structure visualized in a BIM model (own elaboration)

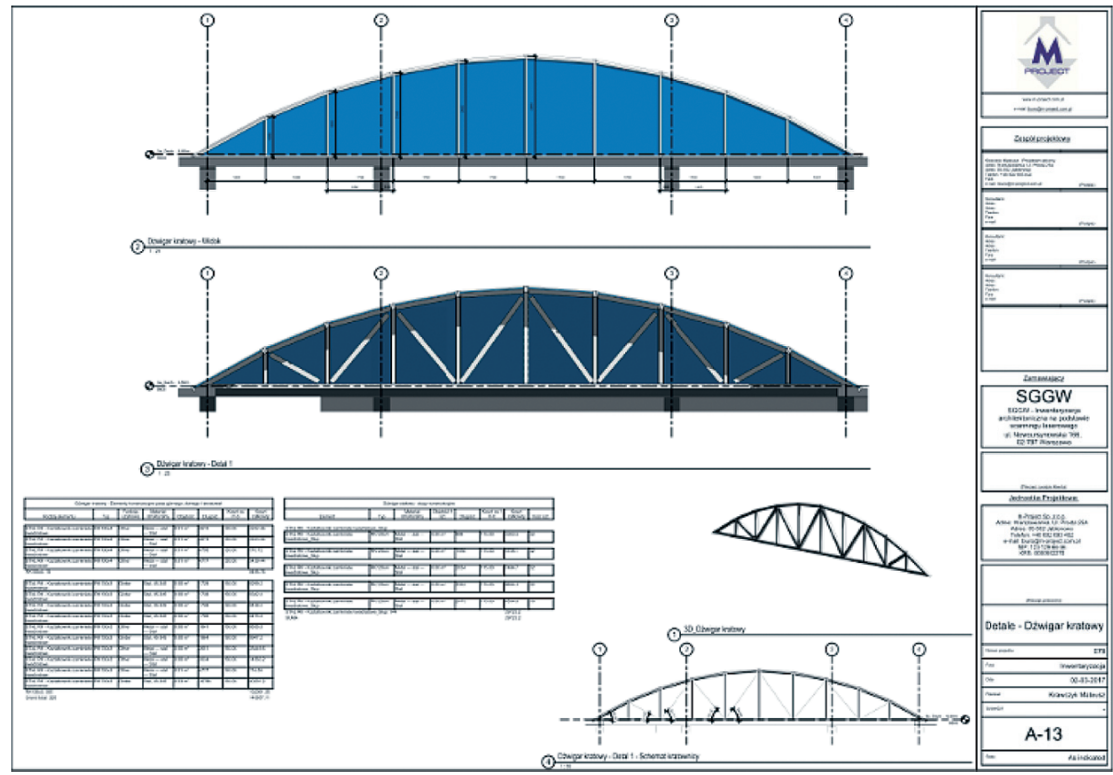

Fig. 10. Example documentation of a construction detail (own elaboration) 
The information contained in BIM might be additionally enriched by BMS system, which in case of the majority of high-volume facilities or public buildings becomes the standard solution. This procedure might consist of disclosing the information necessary to properly manage and administer low-current installations - like alarm, supply or ventilation systems. If we assume that the information transferred by BMS system concerns to a large extent the security aspect of the building management, we could confirm the claims that SHM system should or even have to be an integral part of the solution above. Therefore, it can be concluded that the management of the complex matter of building security from the perspective of existing and functioning model of a building developed in BIM technology should start not later than during the phase of design assumptions.

\section{Conclusions}

The considerations carried out confirmed the thesis that the terrestrial laser scanning technology might be really useful in developing inventory records of an architectonic object in BIM technology. It is very important to keep proper methodology of data acquisition taking into account the principles of correct measurements and their further analysis as well as the processing of registered data with the use of external software. These elements will be the critical aspect in the development of the further 3D model because of their specificity, quality and - above all - accuracy (Fig. 11). The use of documentation developed in this way opens the door to both the effective management of an existing building and recreation of lost or unavailable documentation. Enriching of geometric information gathered during measurement with metadata containing materials, parameters, physical characteristics and age of a building, allows making immediate verification of all renovation assumptions [1].

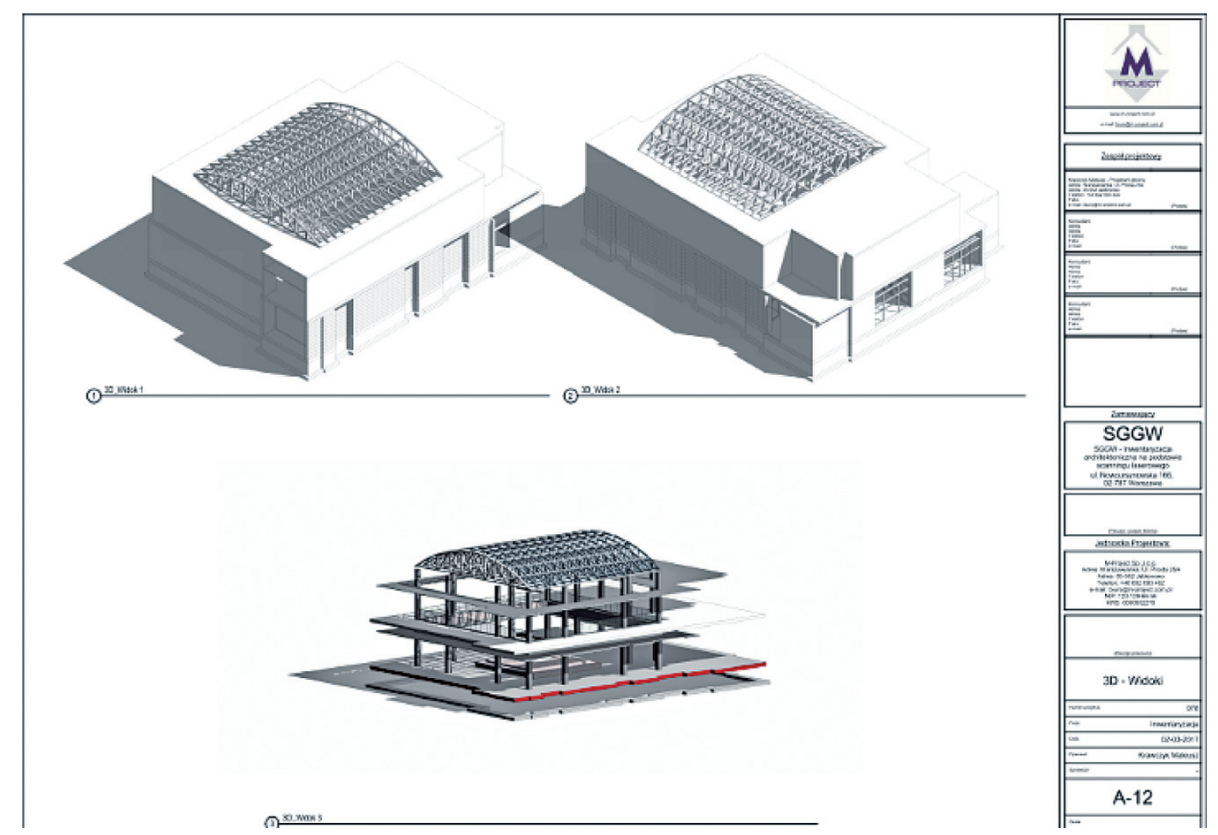

Fig. 11. Views of 3D models of the Water Centre Laboratory, WULS-SGGW in Warsaw (own elaboration) 
The other domain that might significantly benefit from the model developed in such a way is a structural health monitoring system. Namely, taking into account the parameters included in the BIM model, it is possible to design accurate SHM system, which needs to be installed according to factual, accuracy and economic criteria. The versatility of the use of BIM technology improves the management processes considerably and facilitates the designing of SHM systems, which are the fundamental elements of security and risk management of engineering objects.

\section{Acknowledgements}

The authors would like to thank Mr Mateusz Krawczyk of M-Project Sp. z o.o. for his factual and practical input towards this article and Czerski Trade Polska Sp. z o.o. for sharing their laser scanner for the purpose of this research.

\section{References}

[1] BIM Blog, (2017), http://www.bimblog.pl/2016/08/teoria-ewolucji-bim-3d-7d/\#more-3854

[2] BIM Plus, (2017) http://www.bimplus.co.uk/technology/laser-scanning/Stonex X300, http:// www.stonexpositioning.com/index.php/en/products/laser-scanners/x300-detail

[3] Borkowski A.S. Importowanie mapy zasadniczej do modelu BIM, Budownictwo i Architektura 16(3) (2017) 045-051, DOI: 10.24358/Bud-Arch_17_163_05.

[4] Gleason D. Laser Scanning for an Integrated BIM, https://www.tekla.com/de/trimble-5d/laser-scanning-for-bim.pdf, 10.2013

[5] Hardin B., McCool D. BIM and construction management - proven tools, methods and workflows, John Wiley \& Sons Inc. (2015), Indianapolis.

[6] Karsznia K., Wspótczesna technologia skanowania laserowego 3D w monitorowaniu przemieszczeń i deformacji obiektów mostowych, Mosty 1 (2014) 24-27

[7] Kensek K.M., Noble D.E. Building Information Modeling in current and future practice, B., McCool D., BIM and construction management - proven tools, methods and workflows, John Wiley \& Sons Inc. (2014), Hoboken, New Jersey.

[8] SGGW, (2017), http://w3.cem.sggw.pl/centrum-wodne.

[9] Shanbari H.A., Blinn N.M., Issa R.R. Laser scanning technology and BIM in construction management education, (2016), http://www.itcon.org/papers/2016_14.content.09623.pdf.

[10] Stonex X300, User Guide v.5, (2014), http://www.stonexpositioning.com.

[11] Szeląg M., Szewczak A., Brzyski P. BIM in general construction, Monografie Politechniki Lubelskiej (2017), ISBN: 978-83-7947-255-0.

[12] Tomana A. BIM - innowacyjna technologia w budownictwie - podstawy, standardy, narzędzia, Wydawnictwo PWB Media Zdziebłowski Sp. J., (2016), Kraków.

[13] Uchański Ł., Karsznia K. Pomiar inwentaryzacyjny obiektów przemysłowych przy użyciu naziemnego skaningu laserowego w aspekcie wdrażania technologii BIM, Acta Scientarum Polonorum - Architectura, 16(4) (2017) 71-82.

[14] Uchański Ł., Soerensen L. Technologia naziemnego skaningu laserowego w zagadnieniach inżynierii odwrotnej oraz analiz procesów dynamicznych, Archiwum Fotogrametrii i Teledetekcji 21 (2010) 415-424, ISBN 978-83-61576-13-6.

[15] Uchański J., Falkowski P., Uchański Ł. Tradycja i nowoczesność w inwentaryzacji obiektów architektonicznych ze szczególnym uwzględnieniem obiektów zabytkowych, Labor Omnia Vincit Almamer, (2010), Warszawa, ISBN 978-83-60197-96-7, str. 137-167. 
